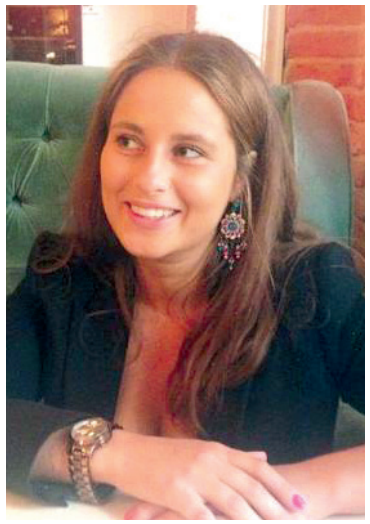

\section{Коломиец Яна Юрьевна}

аспирант кафедры новых медиа и теории коммуникации факультета журналистики, Московский государственный университет имени М. В. Ломоносова, 125009, Российская Федерация, г. Москва, ул. Моховая, 9, e-mail: kolomiets_yana@mail.ru

\section{Yana Yu. Kolomiets}

PhD Student, Faculty of Journalism, Lomonosov Moscow State University, 9 Mokhovaya St., 125009, Moscow, Russian Federation, e-mail: kolomiets_yana@mail.ru

\title{
ПРОГНОСТИЧЕСКИЕ КОНЦЕПЦИИ ХХ ВЕКА: ТЕОРИЯ КОММУНИКАЦИИ ЩТОРОНТСКОЙ ШКОЛЫ» И «НООФСФЕРА» В. И. ВЕРНАДСКОГО
}

\footnotetext{
Аннотация. Статья представляет собой результат теоретического анализа прогностических концепций XX в., важных для понимания современных процессов в развитии медиа.

В частности, в ней рассматриваются концепции основных представителей «Торонтской школы» теории коммуникации - Гарольда Инниса, Маршалла Маклюэна и Уолтера Онга - общей идеей которых является тезис о том, что основной двигатель исторического процесса - новые информационные технологии, кардинально меняющие образ жизни и мышления людей. Также в первой части статьи дается базовое представление о концепции «Ноосферы» В. И. Вернадского, несмотря на явное созвучие с основными положениями теорий информационного общества, ранее не рассматривавшейся в контексте медиаисследований. Выдвигается гипотеза о потенциально высокой ценности теоретического построения В. И. Вернадского в качестве нормативной теории медиа.

Проводится сравнительный анализ описанных теорий с целью выявления точек соприкосновения. А также попытки применить данные теории для интерпретации современных направлений в развитии медиа, которые были спровоцированы появлением новых средств хранения и передачи информации в XX в., получивших колоссальное развитие и способствовавших существенному преобразованию всей системы коммуникации в XXI в.

Ключевые слова. «Торонтская школа» теории коммуникации, «Ноосфера», современные тенденции развития медиа, новые медиа, система коммуникации.

Информация о статье. Дата поступления 7 ноября 2016 г.; дата принятия к печати 19 января 2017 г.; дата онлайн-размещения 31 января 2017 г.
} 


\section{PREDICTIVE MEDIA CONCEPTIONS OF THE 20-TH CENTURY: TORONTO SCHOOL OF COMMUNICATION THEORY AND THE CONCEPT OF NOOSPHERE BY V. VERNADSKY}

\footnotetext{
Abstract. The article analyzes the predictive media concepts of the 20-th century, which are important for understanding the current processes of media development. In particular, the first part of the article examines the concept of the main members of Toronto School of communication theory: Harold Innis, Marshall McLuhan and Walter Ong, the general idea of which is the thesis that the main engine of the historical process is the new information technologies, radically changing the way of people's life and thinking. The first part of the article also provides the basic understanding of the concept of Noosphere by $V$. Vernadsky, which, despite the clear consonance with the basic points of the theory of the information society, has never been considered in the context of media research.

The second part of the article is devoted to a comparative analysis of the theories in order to identify intersection points, as well as to the application of these theories to interpret the current trends of media development, which have been caused by the emergence of new tools of storing and sharing information in the 20-th century, which have received a tremendous development and made a great contribute to a significant transformation of the entire system of communication in the 21-st century.

Keywords. Toronto School of communication theory, Noosphere, current media trends, new media, the system of communication.

Article info. Received November 7, 2016; accepted January 19, 2017; available online January 31, 2017.
}

\section{СБЫВАЮЩИЕСЯ «ПРОРОЧЕСТВА»}

Одно из важнейших качественных изменений, предваряющее переход Биосфреры в Ноосферу «радикальное преобразование средств связи и обмена между странами» [1] - произошло в XX в. с появлением инновационных технологий коммуникации, которые вывели на новый уровень способы взаимодействия человека с информацией и друг с другом. Это теоретическое построение В. И. Вернадского напрямую затрагивает главный тезис теории коммуникации «Торонтской школы»: Medium is the massage [2]. Важна не столько смысловая составляющая сообщения, которое человек передает, сколько медиум (средство), посредством которого он осуществляет эту передачу, те процессы и возможности, которые он открывает.

На сегодняшний день фундаментом современной системы массовой коммуникации в определенной степени можно считать Интернет. Только с декабря 2000 г. по июнь 2016 г. количество пользователей Интернета увеличилось на 900,4 \%, на данный момент уже составляет 3,6 млрд чел., т. е. практически половину $(49,2 \%)$ всего населения планеты ${ }^{1}$, и продолжает расти.

Революционной технологией, кардинально изменившей человека и общество в XXI в., стал переход к интерактивным медиатехнологиям,

${ }^{1}$ По данным Internet World Stats. URL: http: / / www.internetworldstats.com / stats.htm. 
что привело к предсказанному еще футурологами 1970-х стиранию границ между производителями и потребителями информации. Стало возможно появление социальных сетей.

В рамках коммуникативного подхода [3] можно сказать, что на базе технологических изменений коммуникации, описанных выше, стало осуществимо "усиление связей между всеми государствами Земли» [1] еще одно условие возникновения «Сореры разума». Усовершенствование способов коммуникации привело к существенному упрощению процессов обмена информацией, что, в свою очередь, привело к закономерному усилению и упрочению связи между адресатами, в какой бы точке физического пространства они ни находились.

Возвращаясь к образу глобальной деревни Маклюэна [4], можно предположить, что на сегодняшний день Интернет в гораздо большей степени, чем телевидение, является «глобальной нервной системой». Глобальная сеть (сеть сетей, если можно так выразиться) устраняет какие-либо географические границы, воплощаясь в новой системе социальных связей, где взаимодействие людей друг с другом происходит по тому же принципу, что и в племенной деревне: пространственные расстояния предельно малы, все события происходят одновременно, а обмен информацией носит мгновенный характер. Другое дело, что эпоха ранней Ноосферы, скажем так, еще не научилась справляться с рецидивами племенного мышления, так ясно различимыми в сетевых баталиях, где коллективы яростно отстаивают свои картины реальности, демонстрируя лояльность к ценностному ядру своих групп - новых общностей, основанных не на географии, а на интересах, что в целом соответствует уже не деревенской, а «городской» модели социальной сборки, что отмечает, в частности, Иван Засурский, говоря о том, что метафора «глобального города» сегодня представляется гораздо более точной [5]. Однако если рассматривать концепцию академика Вернадского как нормативную, очевидно, что это не предел, а только самое начало становления Ноосферы.

Одним из самых трудновыполнимых, по мнению ряда ученых, условием преобразования Биосореры в Сореру разума является «равенство людей всех рас и религий» [1]. С одной стороны - данное условие действительно представляется невыполнимым по массе причин. Однако с развитием современных средств коммуникации, и, в частности, Интернета, своеобразное равенство, хоть и не сравнимое с равенством, появившимся в мире с разрушением в конце прошлого столетия колониальных империй, действительно привносится в мир анонимностью, возможной в сети.

Если придерживаться логики теории коммуникации «Торонтской школы» [6; 7], практически абсолютное равенство людей в эпоху первичной устности [8] объясняется тем, что все люди обладали примерно одним и тем же набором знаний. Главным способом коммуникации в то время была межличностная коммуникация. И ввиду отсутствия какого-либо способа фиксации знания, люди хранили его в своей памяти. Поскольку объемы запоминаемой информации были ограничены физическими возможностями, обменивались «устные» люди только информацией с высокой степенью актуальности. Все это приводило к тому, что объединенные в общины 
и обменивающиеся необходимыми знаниями посредством устного диалога, люди обладали приблизительно одинаковым информационным аппаратом, что делало их равными. Данное теоретическое построение Вернадского о равенстве людей как об одном из условий перехода Биосферы в Ноосферу, смыкается с представлением Онга об эпохе «Второй устности» [8-10], где электронные средства коммуникации (а на сегодняшний день, в основном Интернет) являются главными «уравнителями» (в данном контексте в положительном смысле этого слова) и осуществляют одно из главных условий перехода человечества в Сореру разума. В эпоху «Второй устности» пока мы можем наблюдать только очертания данного сценария развития отношений между пользователями, которые пока довольно размыты, но уже приобретают определенные черты, в которых угадывается Ноосфера Вернадского.

С другой стороны, очевидно, что масштабная программа оцифровки и освобождения доступа к знаниям и культурным ценностям от технических сложностей и правовых барьеров может оказать сильное стимулирующее влияние на общество в эпоху информации. Ценность концепции Вернадского в том, что она предсказывает не количественные показатели, а качественную трансформацию планетарного масштаба при соблюдении ряда условий. Открытие доступа к знаниям и культурным ценностям является важнейшим условием реализации этой концепции, потому что в других условиях раскрытие потенциала науки и, по Вернадскому, человека невозможно [11].

Важнейший, в рамках нашего исследования, тезис научной мысли
«Торонтской школы» был сформулирован Маршалом Маклюэном: главным следствием развития электронных средств массовой коммуникации является расширение центральной нервной системы человечества [4]. Внедряясь в повседневную жизнь человека, средства коммуникации являются одновременным расширением всех органов чувств и, как следствие, всей центральной нервной системы человечества. А у Вернадского мы читаем: «Младшие современники Ч. Дарвина - Д. Д. Дана (1813-1895) и Д. Ле-Конт (1823-1901), два крупнейших североамериканских геолога (а Дана к тому же минералог и биолог) выявили еще до 1859 г. эмпирическое обобщение, которое показывает, что эволюция живого вещества идет в определенном направлении <...>. Дана указал, что в ходе геологического времени, <...>, т. е. на протяжении двух миллиардов лет, по крайней мере, а наверное много больше, наблюдается (скачками) усовершенствование - рост центральной нервной системы (мозга), начиная от ракообразных, на которых эмпирически и установил свой принцип Дана, и от моллюсков (головоногих) и кончая человеком. <...> Раз достигнутый уровень мозга (центральной нервной системы) в достигнутой эволюции не идет уже вспять, только вперед» [12].

Таким образом, с точки зрения академика Вернадского, расширение центральной нервной системы человечества является вполне закономерным процессом, который вписывается в сценарий исторического развития, разработанный ученым. Однако, согласно концепции исследователя, такое развитие становится возможным только при условии наличия «свободы научной мысли 
и научного искания от давления религиозных, философских и политических построений и создания в государственном строе условий, благоприятных для свободной научной мысли» [1]. Мысль Вернадского о том, что научная мысль и коллективный труд объединенного человечества приведут к переходу Биосферы в Ноосферу, является ключевым тезисом учения. Поэтому данное условие, безусловно, является одним из важнейших. На сегодняшний день степень его осуществления очень разнится в зависимости от страны. Например, в России, где наука чуть более двадцати лет назад была строго регламентирована идеологией страны, это условие можно считать осуществленным - с одной стороны. Несмотря на то, что сегодня наука в нашей стране условно свободна от религиозных, фрилософских или политических рамок, говорить о том, что условия для полноценной свободной научной мысли благоприятны, все же представляется затруднительным. Даже доступ к научной информации затруднен или невозможен.

Вернадский был также крайне обеспокоен «моральным» состоянием науки. Он был одним из первых, кто понял значение и оценил открытие супругов Кюри и Беккерля. В 1910 г. в речи, произнесенной на ежегодном заседании наук, он высказал мысль о том, что с открытием радиоактивности положение человека в мире уже никогда не будет прежним. Исследователь задавался такими вопросами как: сможет ли человек применить силу атомной энергии, использовав ее во благо? Является ли человечество достаточно зрелым для того, чтобы использовать силу, которую ему может дать наука, правильно? Вернадский один из первых обратил внимание ученых на ответственность за свои открытия, что впоследствии стало одним из главных положений экологической философии. Ведь, начиная с древних времен, инновации могли как облегчить жизнь человечества, так и сделать ее невыносимой. Палкой можно копать, а можно - ударить по голове, у огня можно погреться, а можно - в нем сгореть.

В связи с этим невозможно не обратиться к одному из главных «препятствий», существующих на сегодняшний день на пути человечества к Ноосфере. Несмотря на то, что уже сегодня Интернет представляет собой огромную базу знаний на любую тематику, тем не менее говорить о том, что количества качественного контента хватает, чтобы заполнить так называемые knowledge gaps или, в дословном переводе, «пробелы в знаниях" человечества не представляется возможным. Сегодня огромные объемы качественной информации все еще находятся в неоцифрованном виде, а к каким-то информационным пластам нет доступа ввиду различных устаревших аспектов действующего закона «Об авторском праве».

Вернадский в неменьшей степени, чем представители «Торонтской школы», задумывался о том, что для дальнейшего полноценного развития человечеству необходима «продуманная система народного образования и подъем благосостояния трудящихся» [1].

В дописьменный период развития цивилизации структура системы коммуникации носила иной характер: любое общение определялось пространством и временем. Однако с появлением Интернета временные и пространственные границы стираются, и у каждого человека появляется возможность напрямую связываться с другими людьми практически из 
любой точки в пространстве и времени, а еще более простой эту связь делают социальные сети и повсеместная «мобилизация».

На сегодняшний день Интернет в сочетании с социальными медиа представляет собой неопределенное и непознанное коммуникационное пространство, где беспрестанно «обитает мысль» довольно большой части человечества. Внутри этого пространства вовлеченная часть человечества функционирует по принципу коллективного сознания и психологии групп. Но обладает также и потенциалом фоорирования коллективного разума. Благодаря интерактивным медиатехнологиям, появившимся в начале XXI в., участие и активность «человеческой мысли» в пространстве Интернета существенно повысилась. С возникновением социальных сетей, развитием новой открытой системы научной коммуникации и еще большим вовлечением той части человечества, которое задействовано в активной деятельности внутри сетевого пространства, функционирование «человеческой мысли» в Интернете сделало еще один шаг в направлении развития «коллективного интеллекта», но потенциально, по Вернадскому, способно стать сверхмасштабным и осознанным «интеллектуальным коллективом».

Вслед за Вернадским можно предположить, что после определенного уровня насыщения информационно-коммуникационной системы общества научным знанием произойдет тот самый переломный момент, когда развитие центральной нервной системы человечества позволит ему не только ставить вопросы в повестку дня, но и находить их решения, и обеспечивать их реализацию. Так может быть выполнено еще одно из условий, включенных
Вернадским в список необходимых для образования Ноосферы: будучи обеспеченными информацией, люди смогут активно проявлять свою позицию в отношении различных общественно важных аспектов, что приведет к «увеличению роли народных масс в решении вопросов внешней и внутренней политики» [1].

В одной из телеграмм Вернадский пишет Сталину: «Наше дело правое и сейчас стихийно совпадает с наступлением ноосферы - нового состояния области жизни, биосореры - основы исторического процесса, когда ум человека становится огромной геологической планетной силой» ${ }^{2}$. Но интересно, что в архиве РАН хранится две версии этой благодарственной телеграммы, вторая с существенным дополнением. «Наше дело правое. Сверх того, оно стихийно совпадает с ноосферой - новым геологическим состоянием области жизни, когда ум человека становится огромной геологической планетной силой и когда народные массы сами сознательно решают свою судьбу . Какая из них была отправлена Сталину - не известно, как и его ответ.

«Начало преобладания геологической роли человека над другими геологическими процессами в биосфере» ${ }^{3}$ одновременно является и ключевым условием вступления человечества в Ноосферу, и главным тезисом учения Вернадского. В одной из последних работ, опубликованных в книге «Философские мысли натуралиста» по сохранившимся в Архиве АН СССР рукописям, мы читаем « $<. . .>$ основное влияние мысли человека как геологическо-

${ }^{2}$ Архив РАН. Архив акад. В. И. Вернадского. Оп. За. Д. №2008.

${ }^{3}$ Там же. 
го фрактора выявляется в научном ее проявлении: она главным образом строит и направляет техническую работу человечества, переделывающую биосфреру» [12].

Тем не менее, как бы ни были желанны предположения о том, что Ноосфрера уже недалеко, на сегодняшний день условия ее формирования выполнены только частично.

Например, «полное заселение человечеством земного шара», "расширение границ биосферы и выход человека в космос», “открытие новых источников энергии», "равенстве людей всех рас и религий», "разумное преобразование первичной природы Земли с целью сделать ее способной удовлетворить все материальные, эстетические и духовные потребности численно возрастающего населения» [1].

Что же до еще одного условия - «исключения войн из жизни общества» [1], - то говорить сегодня не только о стадии выполнения, но даже о самой возможности его выполнения представляется затруднительным. Однако можно высказать и надежду на то, что потенциал коммуникации всех со всеми, заложенный в новых медиа, в теории способствует формированию более рафинированной системы коммуникации, ориентированной на консенсус [11].

\section{ЗАКЛЮЧЕНИЕ}

Ввиду происходящих изменений (в частности, влияния усовершенствованных информационно-коммуникационных технологий на психологические и поведенческие паттерны человека) мир науки сегодня входит в стадию, названную Т. Куном «экстраординарной» [14]. То есть в стадию, когда реальность начинает наполняться аномалиями - фрактами, которые не всегда можно объяснить с помощью господствующих теорий. Это приводит к постепенной замене их альтернативными теориями, более подходящими для описания новых явлений в определенный исторический период.

В связи с этим представляется уместным высказать также предположение, что данные научные построения, сделанные еще в XX в., действительно являются пригодными для теоретического осмысления некоторых аспектов развития медиа, не поддающихся интерпретации с помощью теорий и концепций, на сегодняшний день господствующих в русскоязычном сегменте медиаисследований.

«Торонтская школа» фокусирует внимание на влиянии медиатехнологии на общество и человека через усиление тех или иных органов чувств, формирование системы представлений о мире, языка и способа передачи информации между людьми, которые в совокупности и формируют наши представления о том, кто такой человек, в каком мире (и обществе) он живет, во что он верит и какой во всем этом видит смысл. Концепция Ноосферы академика В. И. Вернадского полезна тем, что дает способ концептуализации нормативных аспектов теории в контексте научно-технического прогресса. Поразительно, насколько общее направление развития мысли ученого созвучно дискурсу информационного общества и тенденциям развития новых медиа.

В этом смысле концепция Вернадского имеет высокую нормативную ценность, поскольку она предполагает возможность оценки существующей ситуации с позиции внятно изложенной системы взглядов, опирающейся на энциклопедические познания и наработки великого русского ученого. 


\section{СПИСОК ИСПОЛЬЗОВАННОЙ ЛИТЕРАТУРЫ}

1. Яншина Ф. Ноосфера В. Вернадского: утопия или реальная перспектива / Ф. Яншина / / Общественные науки и современность. - 1993. - № 1. - С. 163-173.

2. McLuhan M. The Medium is the Massage: An Inventory of Effects / M. McLuhan, Q. Fiore. - Berkeley : Gingko Press, 1967. - 159 p.

3. Гавра Д. Основы теории коммуникации : учеб. пособие / Д. Гавра. - СПб. : Питер, 2011. $-285 \mathrm{c}$.

4. Маклюэн М. Понимание Медиа: внешние расширения человека / М. Маклюэн ; пер. с англ. В. Г. Николаева. - М. : Кучково поле, 2007. - 464 с.

5. Засурский И. Выступление на конференции IAMCR / И. Засурский // Международная конференция Международной Ассоциации исследователей медиа и коммуникации (IAMCR). Турция, 2011. - Стамбул, 2011.

6. Kerckhove D. McLuhan and the «Toronto school of communication» / D. Kerchhove // Canadian Journal of Communication. - 1989. - Vol. 14, № 4. - P. 73-79.

7. Бакулев Г. П. Массовая коммуникация: Западные теории и концепции : учеб. пособие / Г. П. Бакулев. - М. : Аспект Пресс, 2010. - 192 с.

8. Ong W. J. Orality and Literacy: The Technologizing of the Word / W. J. Ong. - New York : Routledge, 2002. - $202 \mathrm{p}$.

9. Browson W. New Media Literacy in era of Secondary Orality [Electronic resource] / W. Browson. - Mode of access: http://www.academia.edu/518533/New_Media_Literacy_in_ an_Era_of_Secondary_Orality.

10. Bounegru L. Secondary Orality in Microblogging [Electronic resource] / L. Bounegru // Masters of Media. - 2008. - October 13. - Mode of access: http://mastersofmedia.hum. uva.nl/2008/10/13/secondary-orality-in-microblogging/.

11. Засурский И. Инфраструктура Ноосферы [Электронный ресурс] / И. Засурский // Частный Корреспондент. - 2016. - 11 февр. - Режим доступа: http: / / www.chaskor.ru/ article/infrastruktura_noosfery_39825.

12. Вернадский В. И. Философрские мысли натуралиста / В. И. Вернадский. - М. : Акад. проект ; Киров : Константа, 2013. - 522 с.

13. Кун Т. Структура научных революций / Т. Кун. - М. : Прогресс, 1977. - 300 с.

\section{REFERENCES}

1. Yanshina F. Noosphere by V. Vernadsky: a Utopia or a Real Perspective. Obshhestvennye nauki i sovremennost = Social Sciences and Modernity, 1993, no. 1, pp. 63-173. (In Russian).

2. McLuhan M., Fiore Q. The Medium is the Massage: An Inventory of Effects. Berkeley, Gingko Press, 1967. 159 p.

3. Gavra D. P. Osnovy teorii kommunikatsii [Basic Theory of Communication]. Saint Petersburg, Piter Publ., 2011. 285 p.

4. McLuhan Marshall. Understanding Media. The extensions of Man. New York, McGraw Hill, 1964. 389 p. (Russ. ed.: McLuhan M. Ponimanie media: vneshnie rasshireniya cheloveka. Moscow, Kuchkovo pole, Publ., 2007. 464 p.).

5. Zasurskii I. International Association for Media and Communication Research conference speech. Mezhduarodnaya konferentsiya Mezhdunarodnoi Assotsiatsii issledovatelei media i kommunikatsii (IAMCR). Turtsiya, 2011 [International Conference International Association for Media and Communication Research (IAMCR), Turkey, 2011]. Stambul, 2011. (In Russian).

6. Kerckhove D. McLuhan and the «Toronto school of communication». Canadian Journal of Communication, 1989, vol. 14, no. 4, pp. 73-79.

7. Bakulev G. P. Massovaya kommunikatsiya: zapadnyye teorii $i$ kontseptsii [Mass Communication: Western Theories and Concepts]. Moscow, Aspekt Press, 2010. 192 p.

8. Ong W. J. Orality and Literacy: The Technologizing of the Word. New York, Routledge, 2002. 202 p.

9. Browson W. New Media Literacy in era of Secondary Orality. Available at: http:// www.academia.edu/518533/New_Media_Literacy_in_an_Era_of_Secondary_Orality. 
10. Bounegru L. Secondary Orality in Microblogging. Masters of Media, 2008, Octouber 13. Available at: http://mastersofmedia.hum.uva.nl/2008/10/13/secondary-orality-in-microblogging/.

11. Zasurskii I. Noosphere Infrastructure. Chastnyi Korrespondent = Chastniy Correspondent, 2016, February 11. Available at: http://www.chaskor.ru/article/infrastruktura_noosfery_39825. (In Russian).

12. Vernadskii V. I. Filosof skie mysli naturalista [Natural Scientist's Philosophcal Ideas]. Moscow, Akademicheskii proekt Publ., Kirov, Konstanta Publ., 2013. 522 p.

13. Kun T. Struktura nauchnykh revolyutsii [Scientific Revolutions Structure]. Moscow, Progress Publ., 1977. 300 p.

\section{БИБЛИОГРАФИЧЕСКОЕ ОПИСАНИЕ СТАТЬИ}

Коломиец Я. Ю. Прогностические концепции XX века: теория коммуникации «Торонтской школы» и «Ноофсфера» В. И. Вернадского / Я. Ю. Коломиец / В Вопросы теории и практики журналистики. - 2017. - Т. 6, № 1. - C. 128-136. - DOI : 10.17150/23086203.2017.6(1).128-136.

\section{REFERENCE TO ARTICLE}

Kolomiets Ya. Yu. Predictive Media Conceptions of the 20-th Century: Toronto School of Communication Theory and the Concept of Noosphere by V. Vernadsky. Voprosy teorii i praktiki zhurnalistiki $=$ Theoretical and Practical Issues of Journalism, 2017, vol. 6, no. 1, pp. 128-136. DOI: 10.17150/2308-6203.2017.6(1).128-136. (In Russian). 